\title{
Building information modeling (BIM) application in civil constructions intending the increase of service life
}

\author{
A. Marchini $^{1}$ (I) J. O. Patzlaff ${ }^{1}$
}

Received: 27 June 2016/Accepted: 5 October 2016/Published online: 2 November 2016

(C) Springer International Publishing Switzerland 2016

\begin{abstract}
The use of building information modeling methodology in project design and planning of civil construction processes can contribute throughout the building lifecycle. In the various stages, the degree of assertiveness tends to increase because the information is worked together, allowing a better understanding of the details to be met. In addition, to facilitate the implementation, this process can also work in the post-project phase, through the support to the user before the need of building maintenance. These two stages, construction process and after work, when worked together, can directly influence the service life of the systems that make up the building. In this context, this paper aims to demonstrate how the project (three-dimensional model) can be worked along in the planning process and how the information on the maintenance process can be linked to the project. Its method consists in the implementation of 4D planning in a building, linking model and schedule, and listing the major maintenance of the major building systems, linking them to the project as parameterized information. Among the results, there is the viability of $4 \mathrm{D}$ planning and the linking of routines associated with the maintenance activities of the building project. Finally, it is concluded that the use of new technologies for the development of projects and support in
\end{abstract}

Electronic supplementary material The online version of this article (doi:10.1007/s41024-016-0009-2) contains supplementary material, which is available to authorized users.

A. Marchini

augustomarchini@hotmail.com

J. O. Patzlaff

jefersonpatzlaff@gmail.com

1 UNISINOS, Av. Unisinos, 950, Bairro Cristo Rei, São Leopoldo, RS CEP 90.022-750, Brazil the planning stages can directly influence the quality of the enterprise and the service life of the buildings when used properly.

Keywords BIM · Management · Planning · Design ·

Service life $\cdot$ Construction $\cdot$ Maintenance

\section{Introduction}

The building information modeling (BIM), has become a promising field in regards of the integration and compatibility of both projects and information, as in planning, management, projective or executive, providing support to the steps of the construction process [1]. This technology is no longer seen only as a non-conformities or conflicts identifier through the integrating process management activities, resulting in a higher degree of reliability and quality by reducing design errors and thus reducing costs [2].

The technology can also assist in the information in a management context where the whole process of implementation of buildings is based on paper documents, generating such a large volume of material that facilitates the occurrence of errors that bring consequences to the project, usually associated with unforeseen costs. BIM technology incorporates all relevant information to the project in a single model, reducing the possibility of the occurrence of errors and increasing the speed of communication [1].

In this context, the possibility of integrating a threedimensional model of the building in their planning, becomes important in the management of the executional process, where all the elements of the model will be joint together in a particular activity, contributing to its correct execution. This binding process within the architectural 
design methodology is called as the fourth dimension of BIM or BIM 4D methodology.

In addition to the benefits related to the management of the activities with the consequent reduction of failures and increased quality, through BIM 4D there is an improvement in the safety during the work, due to the possibility of virtually planning the construction, including temporary elements such as cranes, trucks, hoists, fences, service elevators, among others [3].

The management of the planned work day by day can also be improved and developed with the help of data provided by BIM tools, due to the ability to generate accurate bills of all stages of work, facilitating the purchase planning and storage of materials. This process makes the job leaner because it optimizes time and space, reducing storage space within the site.

Having access to the model in three dimensions, questions regarding storage sites or even how to perform a certain task can be quickly answered verifying the model. This way, there may be more emphasis on quality of executive steps over tasks of lesser importance of the implementation process [1]. In short, through integrated methodologies of project management, including the sum of many benefits at all stages, there's a tendency to the decrease the construction errors, increasing the construction quality and, consequently, increased service life of the construction or systems that compose it.

Adding to the 4D construction planning process, the benefits can also extend to after work, through the management of building maintenance cycle within the BIM methodology, called the sixth dimension of BIM or BIM $6 \mathrm{D}$, where it's possible to enter information concerning the warranty of equipment, maintenance of equipment and planning systems, manufacturing data and life and even illustrations [4].

In the BIM 6D, the final model will contain all information relevant to the construction described in the operation manual and maintenance of systems, such as preventive maintenance, warranties and specifications. The process of maintenance of buildings is an essential requirement to reach or extend the service life expected the building. Thus it is of utmost importance that maintenance activities are of the user's knowledge, whether through the use of manual and operation or through $6 \mathrm{D}$ BIM models [3]. The maintenance of the building is a set of activities and interventions that must be performed in the building during its service life so that it remains preserved or regain the ability to use [5], and its execution is the user's responsibility [6]. The sixth dimension models can be accessed and viewed by users through facilitated means of view as PDF or 3D PDF due to the need to apply knowledge of BIM software for viewing within the platform.

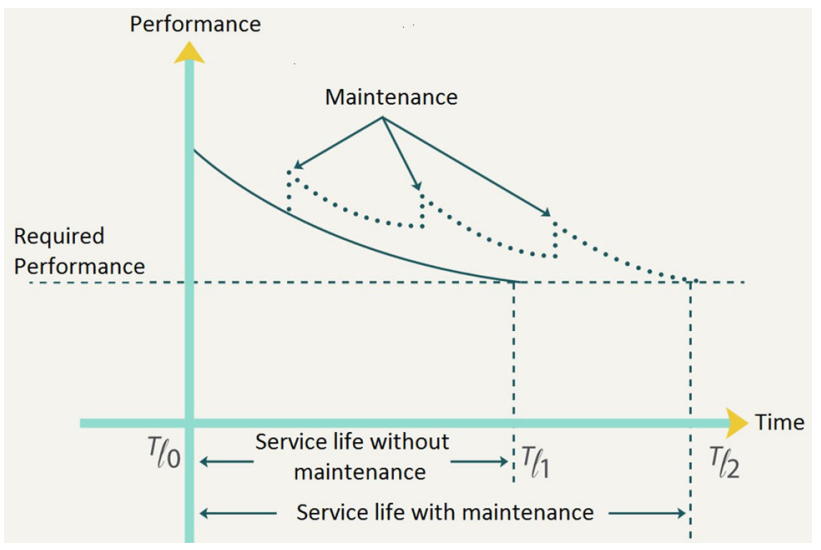

Fig. 1 Performance recovery for maintenance actions [5]

The main objective of this paper is to demonstrate the applicability of BIM in the design phase to ensure a better schedule during the construction phase and also during the service life, through the specification of the needed maintenance of each component of the building. The service life of the building and its systems can be best understood from Fig. 1, which notes the need to perform maintenance processes to achieve it. In the image, "T0" represents the beginning of the service life of the construction, "T1" represents a theoretical service life without maintenance, while "T2" represents a theoretical service life with maintenance.

\section{Research method}

\subsection{Planning management through BIM 4D}

BIM 4D means the integration of schedules with the building's design and 3D model. 4D planning BIM is one of the main applications of this technology, because it gives designers a new way to view the generated schedules, through computer simulations, created by the linking of the construction schedule to the three-dimensional model, enabling the work to be performed as previously defined in the design phase.

For this part of the paper, it was used the design and construction schedule of a multifamily residential condominium, located in the city of Novo Hamburgo, consisting of eighteen high standard two story housing units. The condo is also comprised of a ballroom, playground and guardhouse. The design of this condo was fully realized in BIM, including architectural design, plumbing and structural design, using Revit Architecture.

To start the development of 4D planning, it was attempted to perform two activities schedules so that they could later be compared side by side in video form. Thus two schedules were prepared, called A and B, using 
Microsoft Project. The schedule A refers to the initial proposal of the work, disregarding any delays resulting from climatic variations, the delivery of materials and lack of manpower. The B schedule is the schedule supposedly real (at the end of the production period), covering all possible delays that may occur during the implementation period. The schedules have been created in this way because of the inability to be based on a real schedule of implementation due to fact that there has not been any activity of this kind during the development of this research. Thus, in the schedule B it was added a correction factor of $30 \%$ to simulate the possible delays during the construction period.

To do the integration of schedules developed, Autodesk Navisworks was used. The software has the function to associate the schedule to their respective items on the three-dimensional model, generating, automatically, virtual simulations of the building. In a previous analysis, focusing only on schedule simulation the designer can already see the building being built virtually, according to the schedule created and examine whether the steps thought initially comply with the predictions, or if you can optimize the schedule through better sequencing activities.

In a second step, in possession of the two simulations, it is possible to perform the comparison of both. Thus the simulations were compared and placed side by side, in the form of video, enabling a new way of viewing the stages of progress of the two schedules. This procedure has the main function of allowing the comparison of the difference between the timelines, that is, to provide a physical and comparative visualization of the stages of progress of the work, delays or advances, which is usually given in days and months in the three-dimensional model, in addition to providing a tool that allows new and different analyzes on the schedule.

\subsection{Management building maintenance process}

The ABNT NBR 15575-1:2013 (Brazil's residential building's performance standard) made the role of the owner or user even more important in the maintenance process and the life cycle of the building systems, because to achieve the proposed service life, its intervention is essential. This process made the development of the manual of use and operation a fundamental requirement for the development of this new and growing need, also seeking new ways to link this information to the project. It is known that BIM platform design allows multiple possibilities of integration, and to include information about maintenance program is one of them. This process of integration of these data aims to facilitate the user maintenance process, in addition to making the design more complete, covering a large part of the building's life cycle.
Having access to the virtual building design, which will contain the maintenance data, the user now has a global vision of the systems that make up the building and their preventive maintenance, as well as a practical view of these local maintenance.

In order to facilitate the linkage of maintenance information to the design of residential condominium mentioned above, it was sought to use methods that the software itself (Revit Architecture) provides, the creation of parameters or maintenance parameters. Revit Architecture is a parametric software, i.e. works by parameters that can be color, type, shape, size, thickness, and any other type of information and detail of the project components. Thus, maintenance of information was linked to the project and their respective systems via a parameter in text form.

To initiate this process, first, a parameter group called maintenance needed to be created. Within this group subparameters were created to the types of maintenance that must be performed in a given family project.

Subsequently to the creation of sub-parameters, they were bound to their respective families, for example, subparameters Maintenance Paint-type have been linked to walls family, maintenance-type glasses were linked to the frames family.

After these bindings were done, spaces are created (white gaps) within the properties of families, so that the maintenance program information is described. Once the necessary information is entered, it can be said that it is already part of the project or family, or the 6D. For this project, it is desired that this information can be viewed on the project, in floor plans, sections, elevations and threedimensional views, so labels for each type of sub-parameter were created, allowing the information to be read in the project and not only within the family of properties.

All information related to the maintenance program of the building systems were based on the Brazil National Guide to Drafting Manual of Use, Operation and Maintenance of Buildings (CBIC, 2014). The CBIC manual follows the guidelines and provisions of the ABNT NBR 14037: 2011 (operating manual, use and maintenance of buildings - content and recommendations for preparation and presentation), ABNT NBR 5674: 2012 (maintenance of buildings-procedure) and ABNT NBR 15575: 2013 (residential buildings-performance). Due to the fact that the maintenance program of the CBIC manual extends to all systems that make up a building, some systems were selected for the demonstration of its application viability. Thus, the frame systems, painting, textures, varnishes, glass and cover were addressed.

The program consists of fifty-two different systems, of which four were chosen to be linked to the project in order to demonstrate the process. The data used in the project are shown in tabular form for each verified system. 
Table 1 Maintenance program for aluminum frames (windows) system Source: Adapted from CBIC (2014) [7]

\begin{tabular}{ll}
\hline Frequency & Activity \\
\hline Every 3 months & $\begin{array}{c}\text { Perform general cleaning of window frames } \\
\text { and components }\end{array}$ \\
$\begin{array}{l}\text { Every 1 year or when } \\
\text { necessary }\end{array}$ & $\begin{array}{c}\text { Tighten the screws, locks or handles and } \\
\text { pulleys } \\
\text { Every 1 year }\end{array}$ \\
& $\begin{array}{c}\text { Check for cracks, gaps in the sealing, fixing } \\
\text { the frames and reconstructing its integrity } \\
\text { where needed }\end{array}$ \\
\hline
\end{tabular}

Table 2 Maintenance program for the system of paintings, textures and varnishes frequency Source: Adapted from CBIC (2014) [7]

\begin{tabular}{cl}
\hline Frequency & Activity \\
\hline $\begin{array}{c}\text { Every } \\
2 \text { years }\end{array}$ & $\begin{array}{c}\text { Review the painting of dry areas and if necessary } \\
\text { repaint them, preventing aging, loss of gloss, peeling } \\
\text { and cracks }\end{array}$ \\
$\begin{array}{l}\text { Every } \\
\text { Repainting walls and ceilings in dry areas } \\
\text { The external areas should have their paint reviewed and } \\
\text { if necessary repainted, avoiding aging, loss of gloss, } \\
\text { peeling and cracking }\end{array}$ \\
\hline
\end{tabular}

Verified systems, periodicity and their maintenance needs are:
(a) Aluminum frames (Table 1);
(b) Paints, textures and varnishes (Table 2);
(c) Glasses (Windows system) (Table 3);
(d) Coverage (Table 4).

All constant maintenance information in the tables, as well as their respective frequencies refer to affectively data related to the project.

\section{Results}

\subsection{Planning management through the BIM 4D}

By defining the activities that will lead the sequencing of the building construction, since the primary steps as cleaning and earthwork to the final steps such as cleaning and inspection, you can set the time required to perform each one of them, based on the experience of previous works. The Schedule A is formed, which at the end of the planning of eighteen units, ballroom and guardhouse, reached 468 days of construction or 22 months. The schedule B, as explained earlier, is the schedule that represents the real execution, which at the end totals 578 working days equivalent to 2 years and 3 months. The two schedules, done in MS Project, have been exported to the Navisworks software, along with the three-dimensional
Table 3 Maintenance program for glass (windows system) Source: Adapted from CBIC (2014) [7]

\begin{tabular}{ll}
\hline Frequency & Activity \\
\hline $\begin{array}{c}\text { Every } \\
1 \text { year }\end{array}$ & $\begin{array}{c}\text { In sets that have tempered glass, inspect the operating } \\
\text { system of springs and hinges and check the need for } \\
\text { lubrication } \\
\text { Check the performance of seals and fastenings of glass } \\
\text { in frames }\end{array}$ \\
\hline
\end{tabular}

Table 4 Maintenance program for the cover system Source: Adapted from CBIC (2014) [7]

\begin{tabular}{ll}
\hline Frequency & Activity \\
\hline $\begin{array}{c}\text { Every } \\
6 \text { months }\end{array}$ & $\begin{array}{c}\text { Check the integrity of the rails, tiles and thermal } \\
\text { protectors and, if necessary, to make cleaning and } \\
\text { repairs, assuring the functionality. In the rainy } \\
\text { season, it is recommended to check weekly }\end{array}$ \\
$\begin{array}{l}\text { Every } \\
1 \text { year }\end{array}$ & $\begin{array}{l}\text { Check the integrity of structural components, seals, } \\
\text { fasteners, and reconstituting and treat where } \\
\text { necessary }\end{array}$ \\
\hline
\end{tabular}

model of the condominium, exported from Revit Architecture.

As stated earlier, the software has the purpose of making the association between each model element and the planning, via an interface that presents together the model and the planning, as can be seen in Fig. 2 .

The integration between the schedule and the three-dimensional model of the condo is performed manually by selecting each model element and linking the desired activity on schedule. For the binding it is necessary that the task is identified as construction, demolition or temporary, as the software plays in different ways depending on the type chosen.

At the end of the linking of all project elements to the timelines within the Timeliner software tool itself, the condominium simulations are generated in the form of video, separately for each linked schedule, allowing them to be placed side by side so that it's possible to compare the site activities during the same working day, as shown in the animation (Online Resource 1). Figure 3 depicts the 510th day of execution of the project, which can be done by comparing images of the differences between each of the schedules, where the blue color represents the activity being performed.

From Fig. 3, it is clear that the schedule A (left) is ahead of the B (based on the schedules elaborated), but has the advantage of the possibility to have a sense and a practical insight of the situation of the works being done in the site in relation to what was originally thought, providing the sectors working on site, another evaluation tool in addition to the schedule on paper or in a spreadsheet, providing resources that facilitate the management of activities. The 
same tool can be used to evaluate various types of schedule, defining what best fits constructively to the company's standards, that is, there are many practical uses in this type of comparison view.

\subsection{Management building maintenance process}

Preventive maintenance of buildings has always been of utmost importance to its life cycle, as they ensure quality, comfort and safety for a longer period. But this is not always the understanding of owners who end up not making the necessary treatment, either by carelessness, forgetfulness or the costs to perform these maintenances. Over time, concerns for the maintenance began to gain more importance, both for manufacturers and for the owners, through the preparation of manuals of use and operation, which must present the terms of warranty and maintenance plans.

A fact that made these interventions become even more important was the emergence of NBR 15575: 2013, because the maintenance is necessary for the systems to reach the Design Service Life, exacerbating the responsibility of owner and/or user facing the maintenance of its building, plus the fact that it is the owner's responsibility to carry them out, as NBR 5674:2012 points out, and meet the provisions of the operating manual and property operation. Within the BIM methodology, there is BIM 6D, which is the denomination of the link between the information in the manual of use and operation, with regard to post-work, i.e. the entire life cycle of the building, after delivering the keys to the owner. Along with the house keys, the manual of use and operation of the building must be delivered to the owner, as well, whose elaboration is of responsibility of the builder or developer. One of the parts of this manual is the maintenance program, which provides a list of key systems that constitute the building and the indication of maintenance and deadlines to be met for each of these systems.

In this way we sought to link the maintenance program of some systems to the project of the residential condominium units mentioned above, aiming to demonstrate the process of executing a 6D model. The analyzed maintenance program was based on the National Guide for the Preparation of the Manual of Use, Operation and Maintenance of Buildings [7].

The linkage of the information shown in the tables above was conducted with Revit Architecture, by creating parameters for each type of maintenance required, allowing the linking of them to the project.

In this software, the project consists of families that must be developed during the design process. In addition to the geometric shape, these families are made up of parameters that characterize the objects as a material, width, length, and every other necessary information of the object. In this way the program allows you to delete, edit and even create new parameters, enabling the inclusion of varied characteristics families.

This process also allows the linking of any kind of information to the project, by setting parameters, to be inserted in text form, or the inclusion of a feature that will not affect the shape or appearance. Through this process, the information becomes part of the object and is linked to it at all locations where it is used in the project.

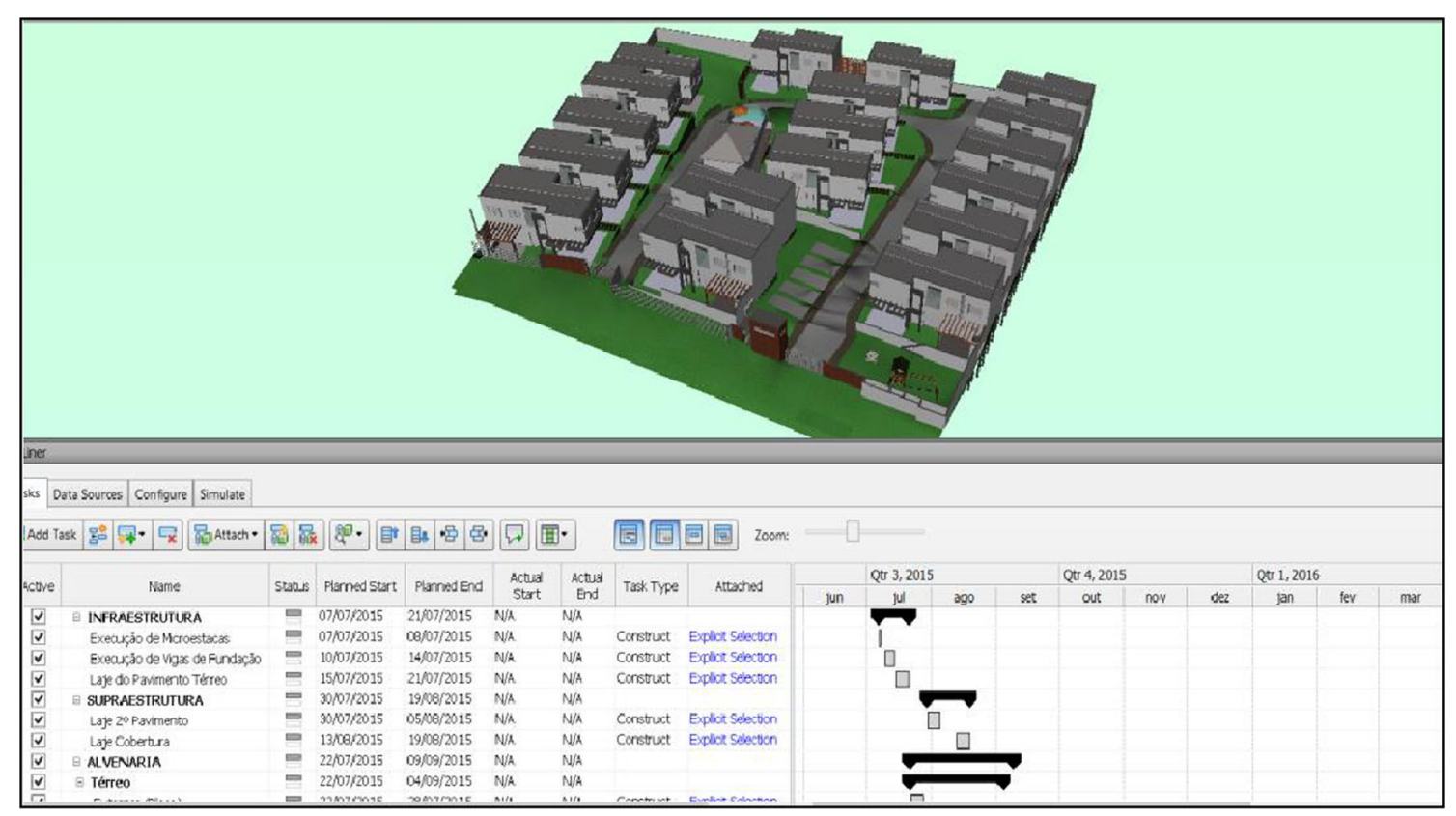

Fig. 2 Example of schedule linking (4thD) on the dimensional model (3D) in the software 


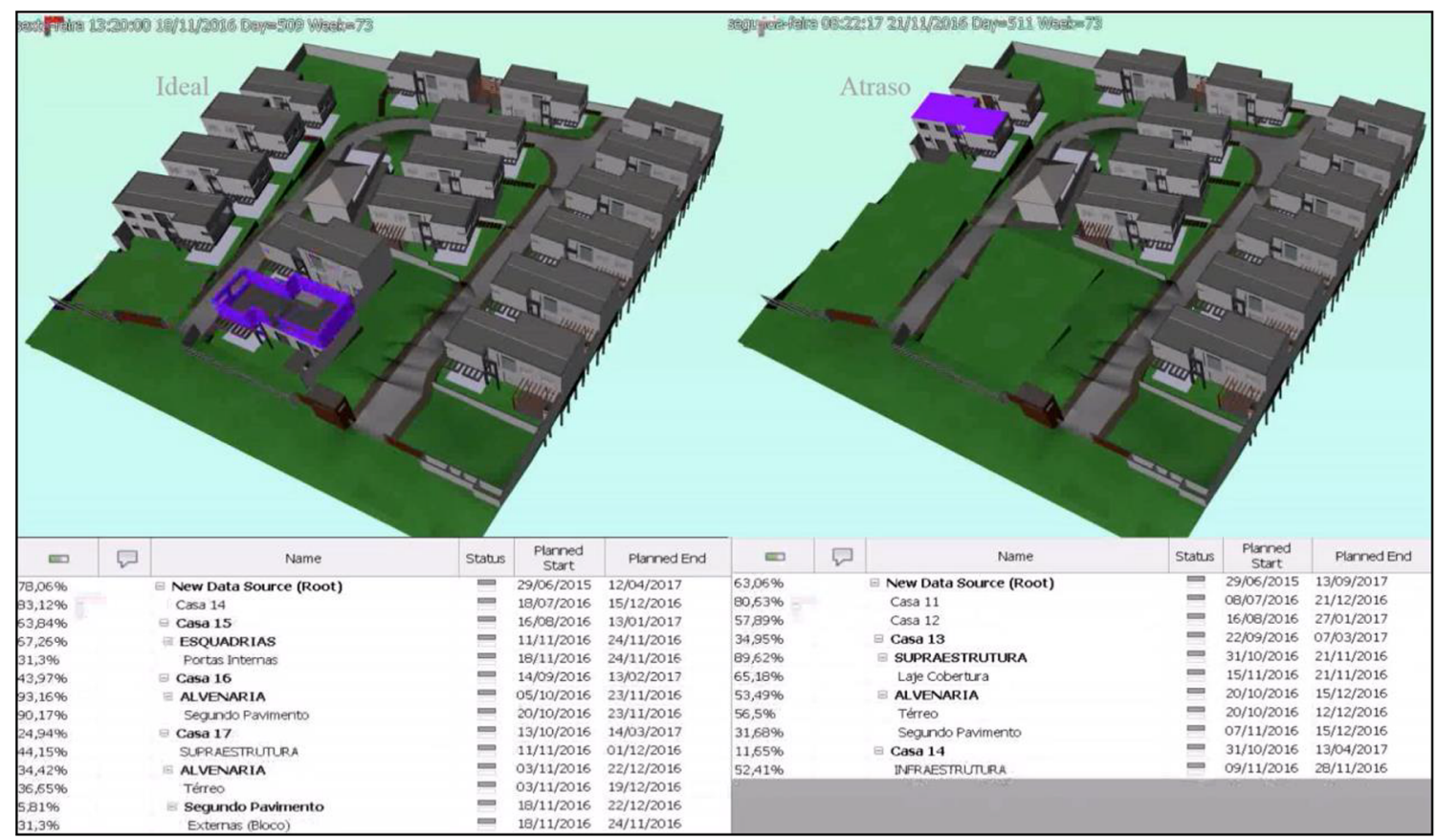

Fig. 3 Comparison of the schedules A (schedule done during the design phase) and B (real schedule) during the 510th day

Thus sub-parameters were created to insert the desired information related to the maintenance program. To create the sub-parameter, a parameter group called maintenance had to be created. Within this group of parameters subparameters were created related to each type of service.

Maintenance sub-parameters were created based on the names of each system, as shown in Fig. 4.

After the creation of all the sub-parameters, it's reported to the software to which family the parameter should be added. The coverage parameters must be added to the roof family, frames parameters to the windows family, painting parameters to the walls family and the glasses parameters as well as the windows family.

Completed the insertion of the parameters of the corresponding families, a field is available in its properties, next to each parameter set up, which is part of the maintenance data of each system, as shown in Fig. 5.

After entering the information for all the parameters created within their corresponding families, the integration of data from the completed maintenance program is considered and linked to the project and the three-dimensional model, making this data part of the families that compose them. Data can be read or viewed through the properties of each system.

The link makes it possible to create automatic labels for identifying information on floor plans, views, elevations, sections and three-dimensional views.

The label serves to identify, automatically, a determined information within the systems that should be indicated by the designer which information you want the label to interpret, so that its needed only to select the family in the project and the information will be searched automatically, becoming visible and indicated through the lines or arrows.

This way, as it's wanted to identify all project parameters, we created a label for each parameter maintenance, so that all data entered are visible in selected views as Figs. 6 and 7.

The integration of the maintenance program in the design meets the objectives of this design methodology, which is to seek the integration of all kinds of information to the project, within a single model capable of portraying all stages of the building, from its initial conception, modeling, construction, life cycle until its final destination, either demolition or reuse. In addition to being linked to the families of the project, this kind of identification allows the user the practical visualization of where maintenance should be made through simplified viewing platforms, such as PDF or 3D PDF. Figure 7 shows the construction in a general point of view, but it's possible to get to more specific details and exact position of maintenance, even in plumbing and electrical systems when modeled.

The maintenance program within the BIM is the first step of linking information comprising the model $6 \mathrm{D}$, in order to have a more complete project within a single platform, not only in manuals or other sources, facilitating the obligations of designers and users.

\section{Final}

The use of more advanced methods for the preparation of projects, in this case referring to the Building Information Modeling can bring some advantages to the project, for the 
Property parameters

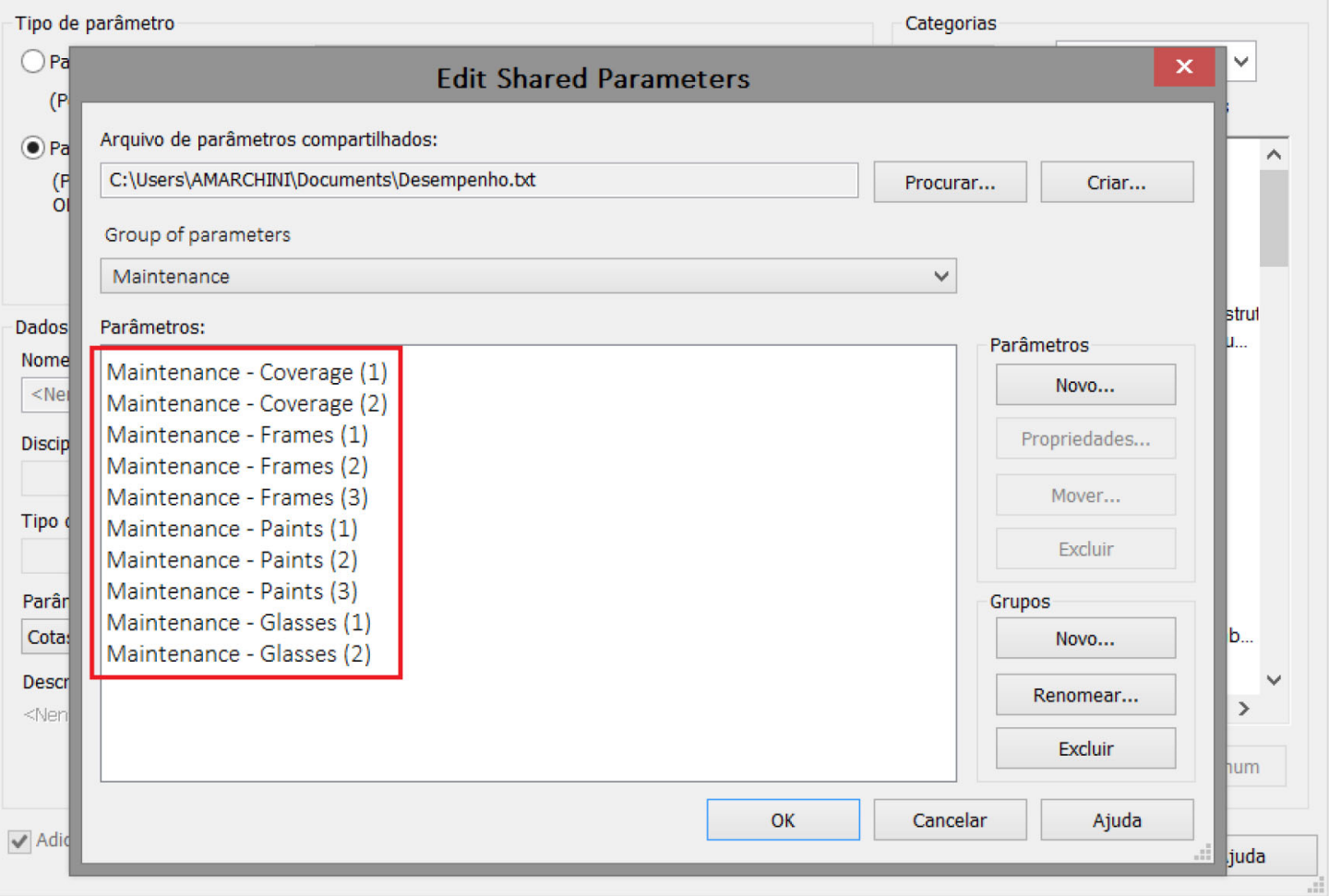

Fig. 4 Creating sub-parameters for the Maintenance Program

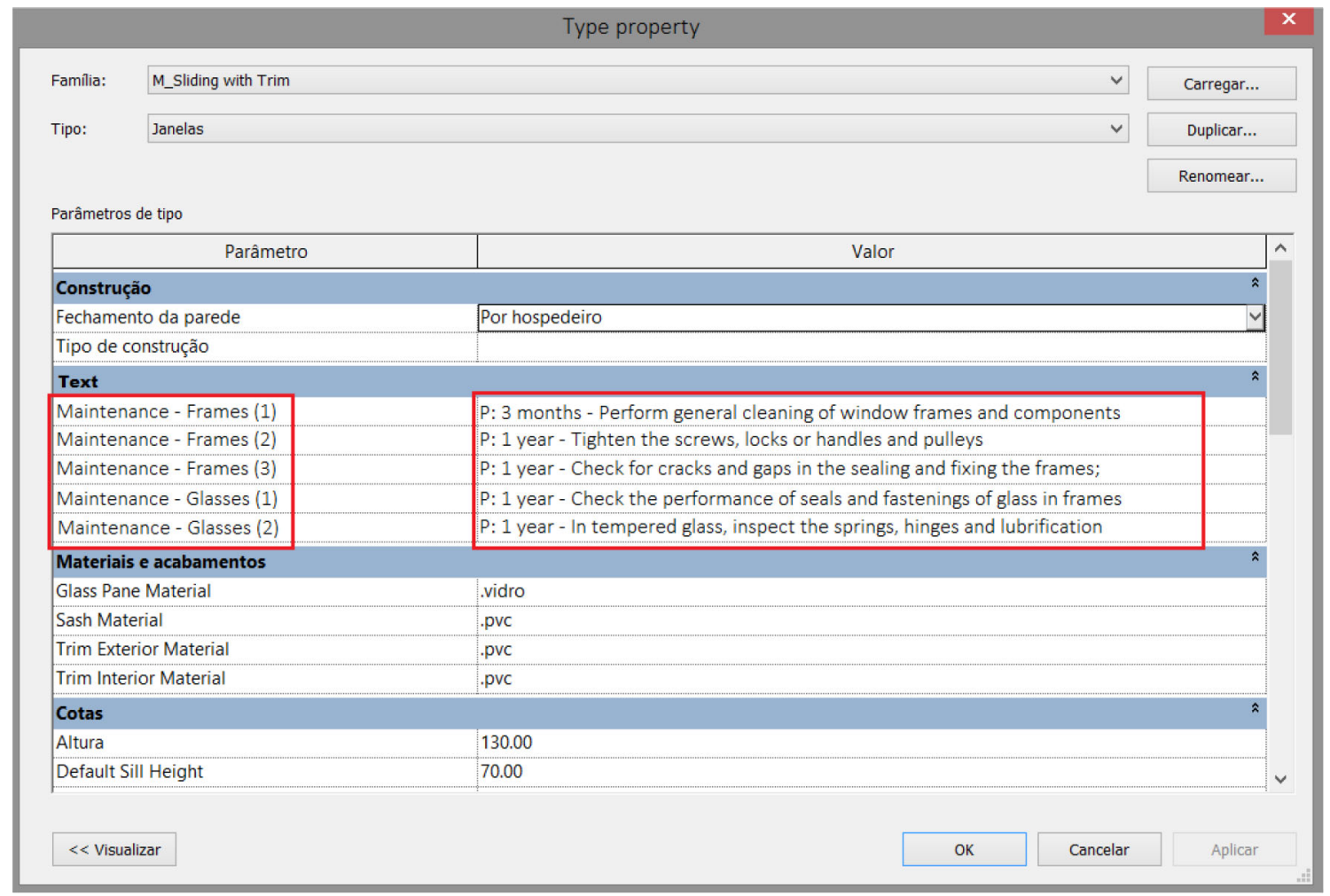

Fig. 5 Inserting the performance specifications of the parameters 


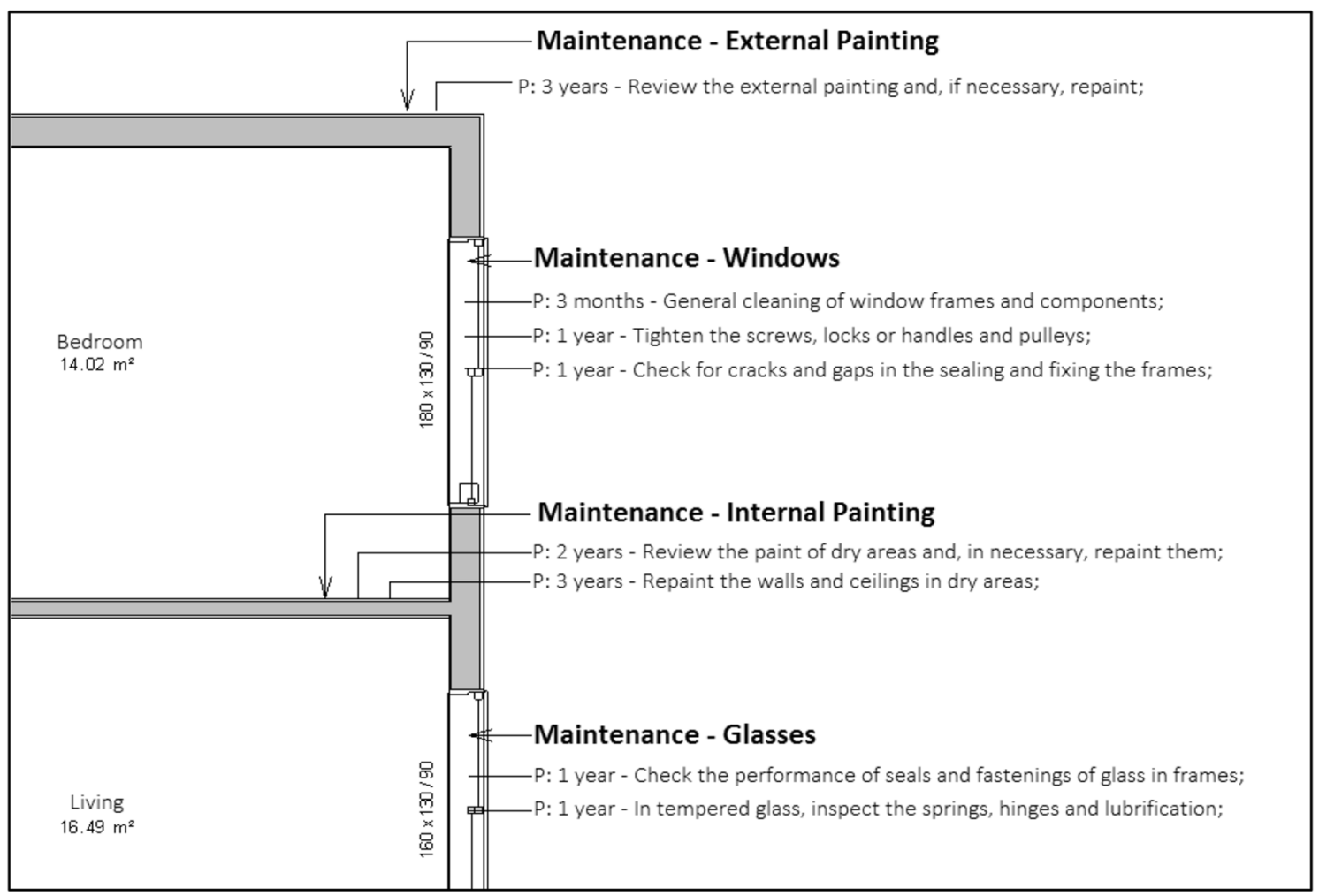

Fig. 6 Identification of the Demo Floor Plan of Maintenance Information for Walls Systems, Frames and windows

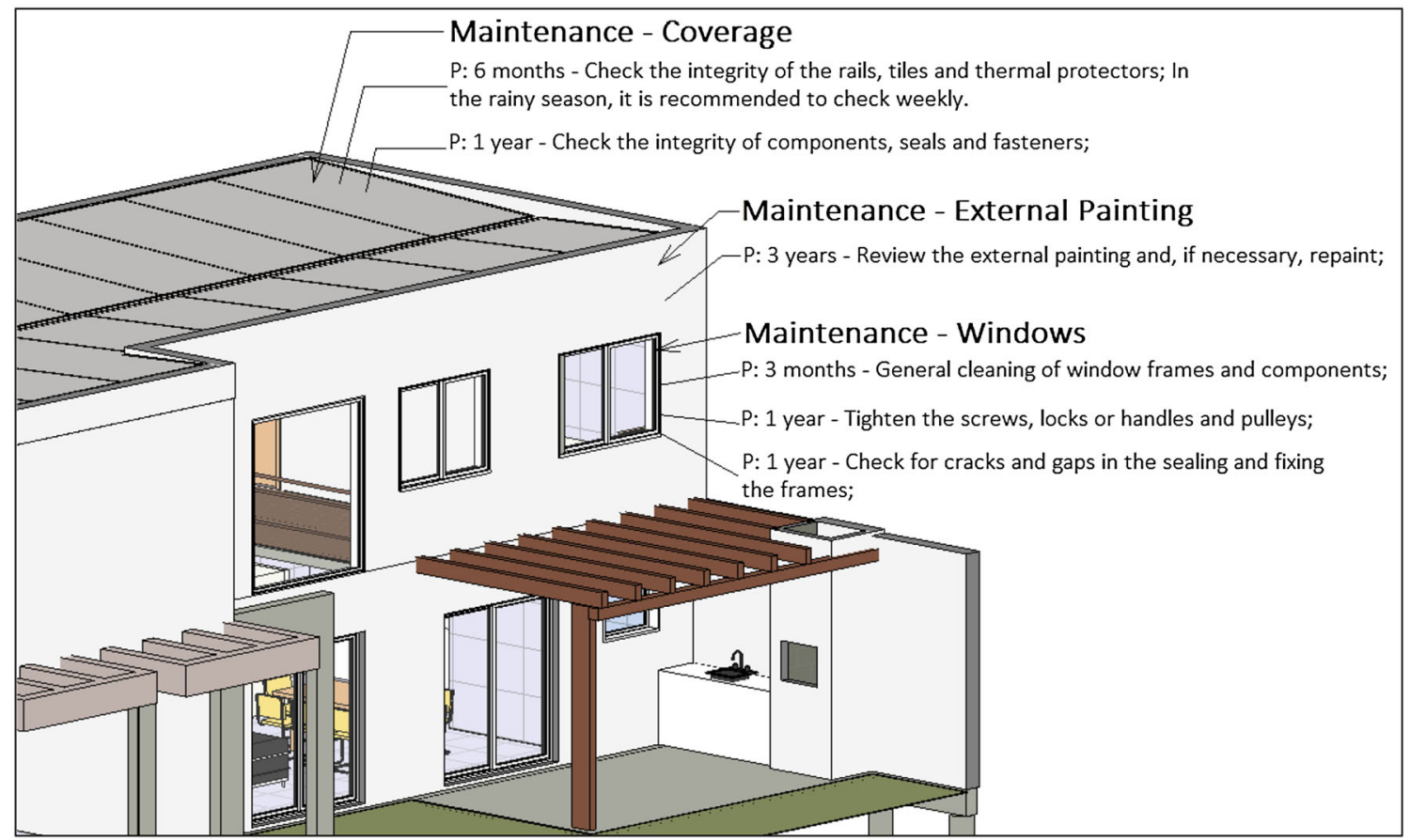

Fig. 7 Identification of the demonstration in view of the three-dimensional Maintenance Information for Walls Systems, Frames, Glass and coverage 
construction and the post-work management. When planning the construction of a building through the BIM 4D methods, the probability of having a better planning tends to increase as the deadlines may be better suited to the tasks (avoiding work overload and consequent decrease in quality), identifying critical tasks and especially defining in project all the details before it goes to the site, reducing decisions in situ, which may end up compromising some systems due to the non-correct procedures performed. Maintenance activities during the life cycle of the building, after the occupation, has a very important role in the conservation of all systems, working directly in the service life of the building. It is known that the performance required over the years tends to diminish, needing these activities to achieve the minimum performance and to increase the time that the building can be used for its original purpose. Thus, it is considered extremely important to the user's role on these activities. The development of the model 6D has to assist the user's role and promote greater effectiveness of maintenance, in cooperation with the use of manual of maintenance and operation. With the $6 \mathrm{D}$ template, the user becomes aware of all systems that compose the building (resulting in a three-dimensional model), and see the exact location where maintenance should be made. That is, the 6D model is a three-dimensional summary maintenance program, where the information is grouped together for each system type and displayed in the project, aiming a better experience and interpretation of the user front before maintenance is needed.

Together, all these steps can actively interfere and allow the considerable increase of service life to the building and systems that make them up. The use of these methods alone do not guarantee the increase of service life to the building, it is necessary that they are well thought out and properly executed to be effective, as a bad project using new methodologies, will remain a bad project regardless of the platform that it is made on. However, on a good design, these methods can bring positive results to the service life and the building as a whole.

\section{References}

1. Eastman C et al (2011) BIM handbook-a guide to building information modeling for owners, managers, designers, engineers and contractors. Digital Version

2. Silva FAC (2015) Construtoras, entidades e fornecedores se mobilizam e aumentam uso do processo de Modelagem da Informação da Construção Civil. Construção, São Paulo, v. 162, jan. http://construcaomercado.pini.com.br/negocios-incorporacaoconstrucao/162/construtoras-entidades-setoriais-e-fornecedoresse-mobilizam-e-aumentam-uso-335413-1.aspx. Accessed 16 Mar 2015

3. Rendeiro JE (2013) Apresentando o BIM-primeira parte. Engenharia do Futuro, 2013. http://engdofuturo.com.br/apresentando-obim-1a-parte/. Accessed 11 Mar 2015

4. Mattos AD (2014) BIM 3D, 4D, 5D e 6D. Pini Blogs. http://blogs. pini.com.br/posts/Engenharia-custos/bim-3d-4d-5d-e-6d-3353001.aspx/. Acesso em 12 Mar 2015

5. Associação Brasileira de Normas Técnicas (ABNT) (2013) NBR 15575-1: Edificações habitacionais-Desempenho-Parte 1:Requisitos Gerais. Rio de Janeiro

6. ASSOCIAÇÃO BRASILEIRA DE NORMAS TÉCNICAS (ABNT) (2012) NBR 5674: Manutenção de edificações-Procedimentos. Rio de Janeiro

7. CBIC (2014) GUIA NACIONAL PARA ELABORAÇÃO DO MANUAL DE USO, OPERAÇÃO E MANUTENÇÃO DAS EDIFICAÇÕES. Brasília, DF 